\title{
A Sound Quality Study of Household Electrical Appliances by Jury Test in Indoor Space
}

\author{
Shu Hua Chang ${ }^{*}, 1$, Hsiao Wen $\mathrm{Wu}^{2}$ and Chen Far Hung ${ }^{1}$ \\ ${ }^{I}$ Department of Engineering Science and Ocean Engineering, National Taiwan University, Taiwan \\ ${ }^{2}$ Department of Electrical Engineering, Tungnan University, Taiwan
}

\begin{abstract}
This paper establishes a procedure for the evaluation of human hearing perception in indoor spaces by jury testing. An artificial head system was used to record indoor noise and to determine physical acoustic and psychoacoustic parameters within living and working environments. This test involved a jury consisting of 102 people of different ages, genders and occupations. The subjects participated in the sound quality evaluation and from this; indicators of human perception to sound were obtained.

Three types of residential spaces in which to carry out the jury test were selected, including a high-rise apartment, a general residential apartment and a small apartment suite. A workspace in the form of a medium-sized meeting room was also tested. The paired comparison method and the category judgment method were both utilized in the jury test questionnaire. The paired comparison method was used to evaluate the psychoacoustic perception of loudness and sharpness, while the category judgment method applied a seven-point scale. Psychoacoustic parameters were used to analyze human hearing responses; from these, perceived sound quality was established for each subject. Through this testing procedure, a reasonable sound quality evaluation method was established.
\end{abstract}

Keywords: Hearing perception, jury test, loudness, psychoacoustics, sound quality, sharpness.

\section{INTRODUCTION}

In recent years, there has been an increased emphasis on the sound quality in indoor living spaces. Improved sound quality in living spaces enables human beings to experience a more comfortable environment. However, it is challenging to define sound quality because human hearing implies subjective perception [1, 2]. NC and NR curves are commonly used to rate indoor noise. Indoor sound quality is typically assessed by measuring the sound level of background noise using a single Type 1 or Type 2 microphone. Generally, the microphone is not designed to simulate the human auditory system, and measurement data obtained using a single microphone does not consider human binaural hearing $[3,4]$. Therefore, such measurement data cannot satisfactorily quantify human auditory perception. Sound level meters are generally fitted with the A-weighting scale to reflect the response of the human ear. The Aweighting scale is now used universally. However, the scale does not take all human psychological factors into account. Similarly, a measured sound pressure level is not adequate to characterize the sound quality within a room.

In order to determine sound quality one must experience a subjective auditory event while a source is emitting sound. There are multiple aspects to sound quality such as

*Address correspondence to this author at the Department of Engineering Science and Ocean Engineering, National Taiwan University, Taiwan;

Tel: +886-2-33663366-51208; Fax: +886-2-33663251;

E-mail: d92525006@ntu.edu.tw psychoacoustics, physics, and space design. Psychoacoustics is important when evaluating sound quality. The sound quality evaluation procedure involves human subjects and provides different ways to rank or scale sound events [5-8]. The procedure involves recording sound samples with an artificial head system, and requires that the subjects listen to the sound samples through headphones. The purpose of this is to create an environment that simulates a subject sitting in an indoor space $[9,10]$.

This jury test procedure can also help define a psychoacoustic criterion relating to sound quality in indoor spaces. The use of this criterion as an objective sound quality standard or as a framework to improve sound quality control is proposed.

\section{PSYCHOACOUSTICS PARAMETER}

Psychoacoustics is concerned with the human auditory response to sound. Psychoacoustic parameters are used to quantify human judgments of various sounds. This study used two psychoacoustic parameters to evaluate the sounds of household electrical appliances.

\subsection{Critical Bands}

The human ear can generally respond between the audible frequency range of approximately $20 \mathrm{~Hz}$ to $20 \mathrm{kHz}$, and is the most sensitive between $2 \mathrm{kHz}$ to $4 \mathrm{kHz}$. However, sensitivity to certain frequencies varies between individuals. Therefore, the audible frequency range is divided into 24 critical bands [11], which are based on the "Bark" scale. The conversion formula is presented as equation (1). 
$\mathrm{B}=13 * \tan ^{\wedge}(-1)\left((0.76 * \mathrm{f} / 1000)+3.5 * \tan ^{\wedge}(-1)\left((\mathrm{f} / 7500)^{\wedge} 2\right)(1)\right.$

\subsection{Loudness}

Loudness, expressed in "phon," is the psychoacoustic parameter corresponding to the perceived level of sound. It is an important factor of sound quality, and implies the degree of sound energy and the loudness level.

In addition to the unit of loudness, "sone" is a unit that quantifies the sensation of loudness. The main distinction between loudness sensation and loudness level is the scale associated with the loudness of a sound. For instance, the level of $40 \mathrm{~dB}$ at a $1000 \mathrm{~Hz}$ reference frequency gives reference to loudness sensation, or 1 sone. On the other hand, when the level of the $1000 \mathrm{~Hz}$ tone is increased by 10 $\mathrm{dB}$ the sensation of loudness is increased by a factor of two. "Sone" and "phon" conversion formulas are shown in equations (2) and (3).

sone $=2^{\wedge}(($ phon -40$) / 10)$

phone $=40+10 \log _{2}$ sone

According to the International Standard ISO532B, the Zwicker loudness method is based on spectral analysis using specific loudness N', in Sones / Bark. The specific loudness is used to define the loudness of each critical band and is calculated as shown in equation (4) [12].

$\mathrm{N}=\int_{0}^{24 \mathrm{Bark}} \mathrm{N}^{\prime} \mathrm{dz}$

\subsection{Sharpness}

Sharpness is measured in acum and refers to a sensation value. It is a measure of the ratio of high frequencies to the overall level. More specifically, it is the integration of specific loudness multiplied by a weighting function, divided by total loudness, where the specific loudness exhibits the distribution of loudness across the critical bands. Hence, sharpness is level independent. Normalized to a reference sound, a narrow band of noise centered at $1 \mathrm{kHz}$ at a level of $60 \mathrm{~dB}$ and a bandwidth of $160 \mathrm{~Hz}$, has an agreed sharpness value of one acum.

\section{METHODOLOGY OF JURY TEST}

The main purpose of this paper is to study the human auditory response to indoor noise by using the artificial head system as a measurement tool. Test rooms comprised four types of indoor spaces with different characteristics. Noise sources included six types of household electrical appliances.

\subsection{Measurement of Indoor Spaces}

The four types of indoor spaces used are as follows: Room 1 (R1) is a high-rise apartment measuring $10 \times 23.1 \mathrm{~m}$ (see Fig. 1); a background noise level of $43.35 \mathrm{~dB}$ was measured in this space. Room 2 (R2) is a general residential apartment measuring $10.75 \times 10.75 \mathrm{~m}$ with a background noise level of $56.75 \mathrm{~dB}$ (see Fig. 2). Room 3 (R3) is a small apartment suite measuring $5.8 \times 4.8 \mathrm{~m}$ with a background noise level of $49.71 \mathrm{~dB}$ (see Fig. 3). Room 4 (R4) is a medium sized workspace consisting of a meeting room measuring $6.3 \times 4.8 \mathrm{~m}$ with a background noise level of $53.92 \mathrm{~dB}$ (see Fig. 4).

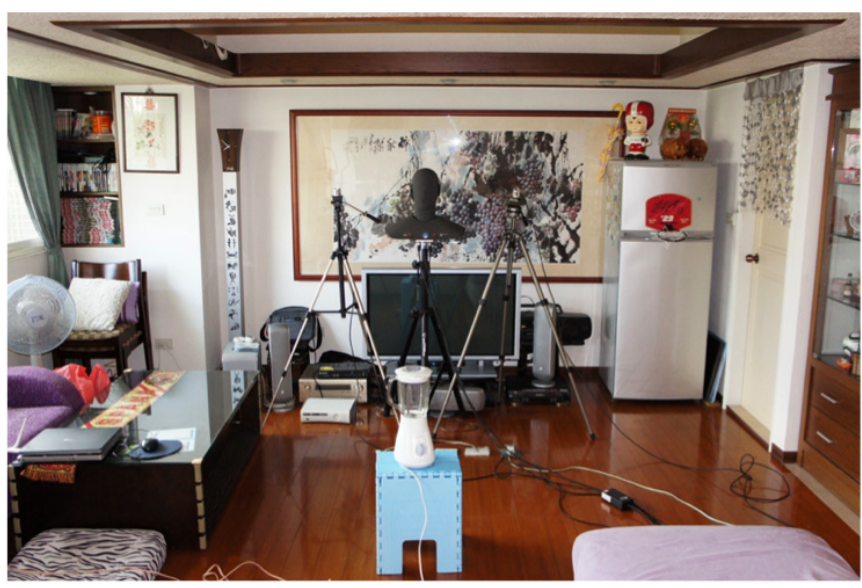

Fig. (1). Indoor space layout of high-rise apartment.

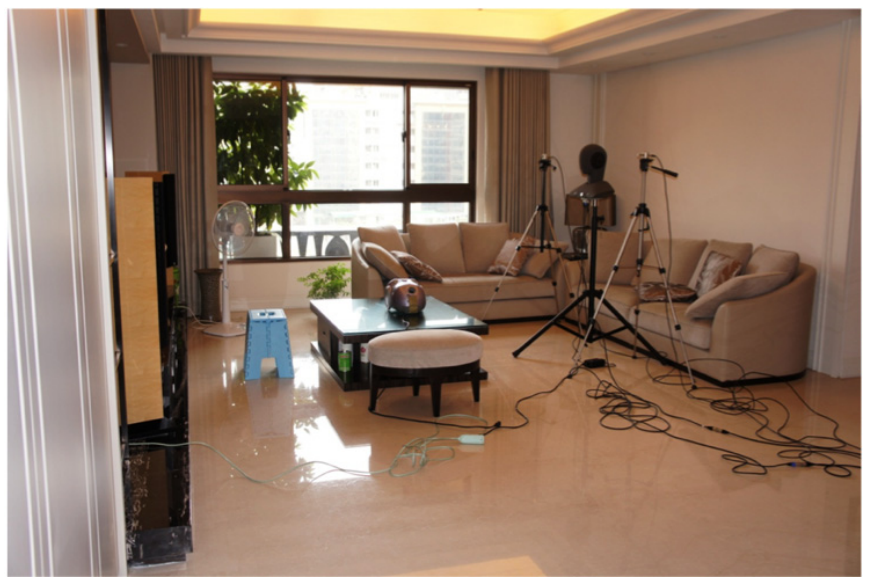

Fig. (2). Indoor space layout of general residential apartment.

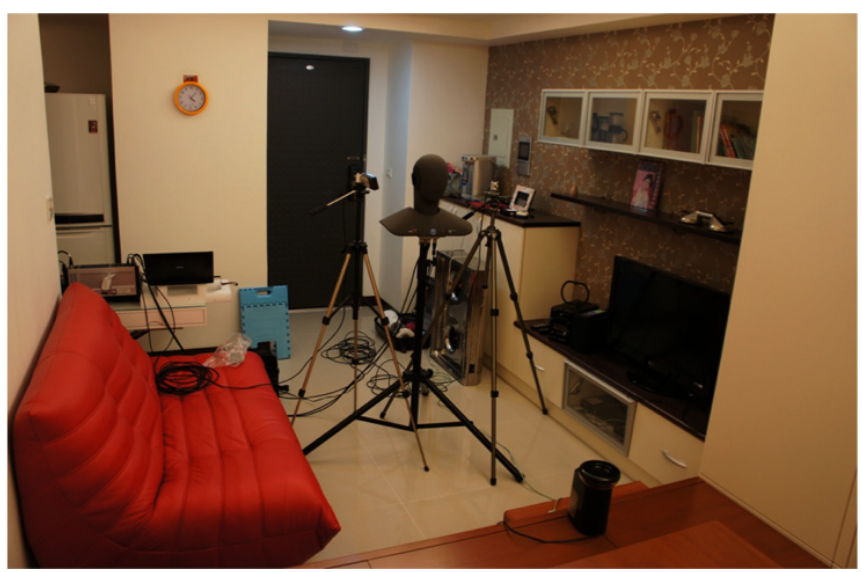

Fig. (3). Indoor space layout of small apartment suite.

These four types of indoor spaces represent the most common sizes of residential and workspaces in Taiwan. The noise sources were recorded using an artificial head HMS IV.0 (HEAD acoustics). The artificial head was placed in an area most frequently visited by the residents or workspace users. The distance between the electrical appliances and the artificial head was maintained at $1.5 \mathrm{~m}$. The artificial head was placed $1.2 \mathrm{~m}$ above the local floor level. Fig. (5) shows the indoor space layouts adopted throughout the testing procedure. 


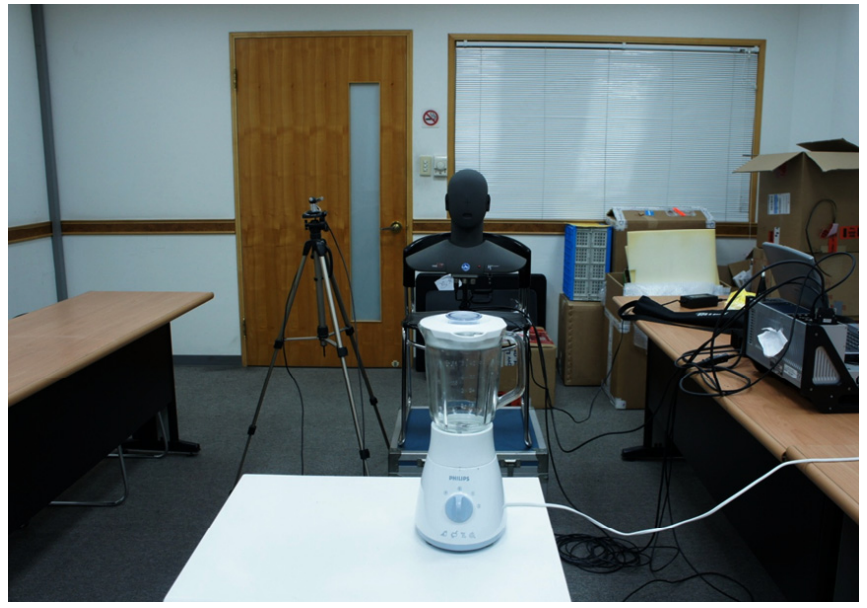

Fig. (4). Indoor space layout of meeting room.
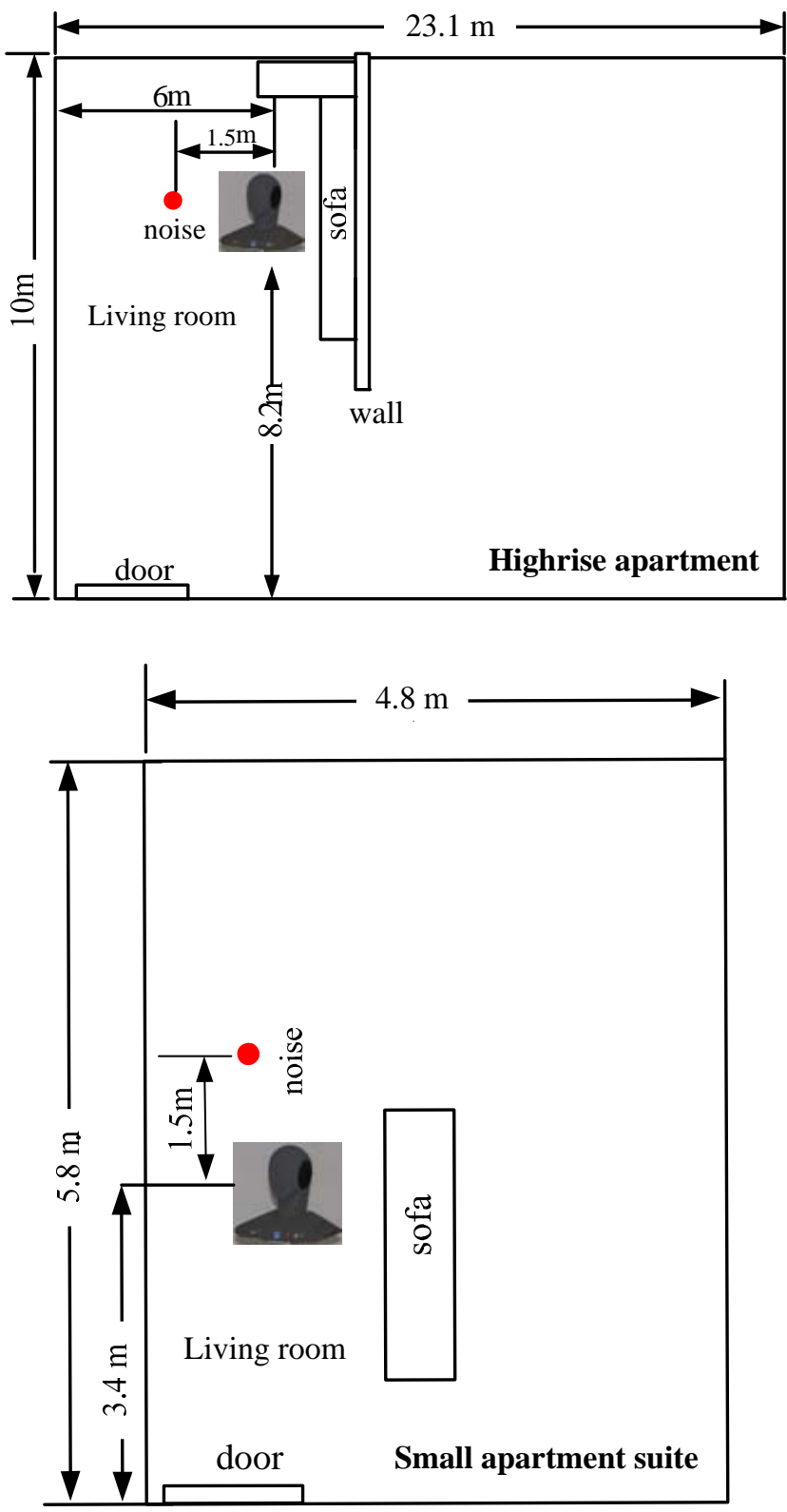

\subsection{Measurement Instruments}

The noise sample recording system for a hearing perception test must maintain high and consistent quality. To provide the subjects with an authentic spatial sound environment, artificial head recording was employed. This recording method is equipped with playback technology. Artificial head technology enables the subjects to feel like they are in the original sound field during noise signal playback. Measurements and recording of noise sources are carried out by the artificial head binaural recording system HEAD acoustics HMS IV.0, which is a multichannel data collector. The analysis software used was HEAD acoustics SQLab III, ArtemiS. The playback and listening jury test system used HEAD acoustics PEQ and Square. The reference microphones used included GRAS Type I, 40AE, 26CA.

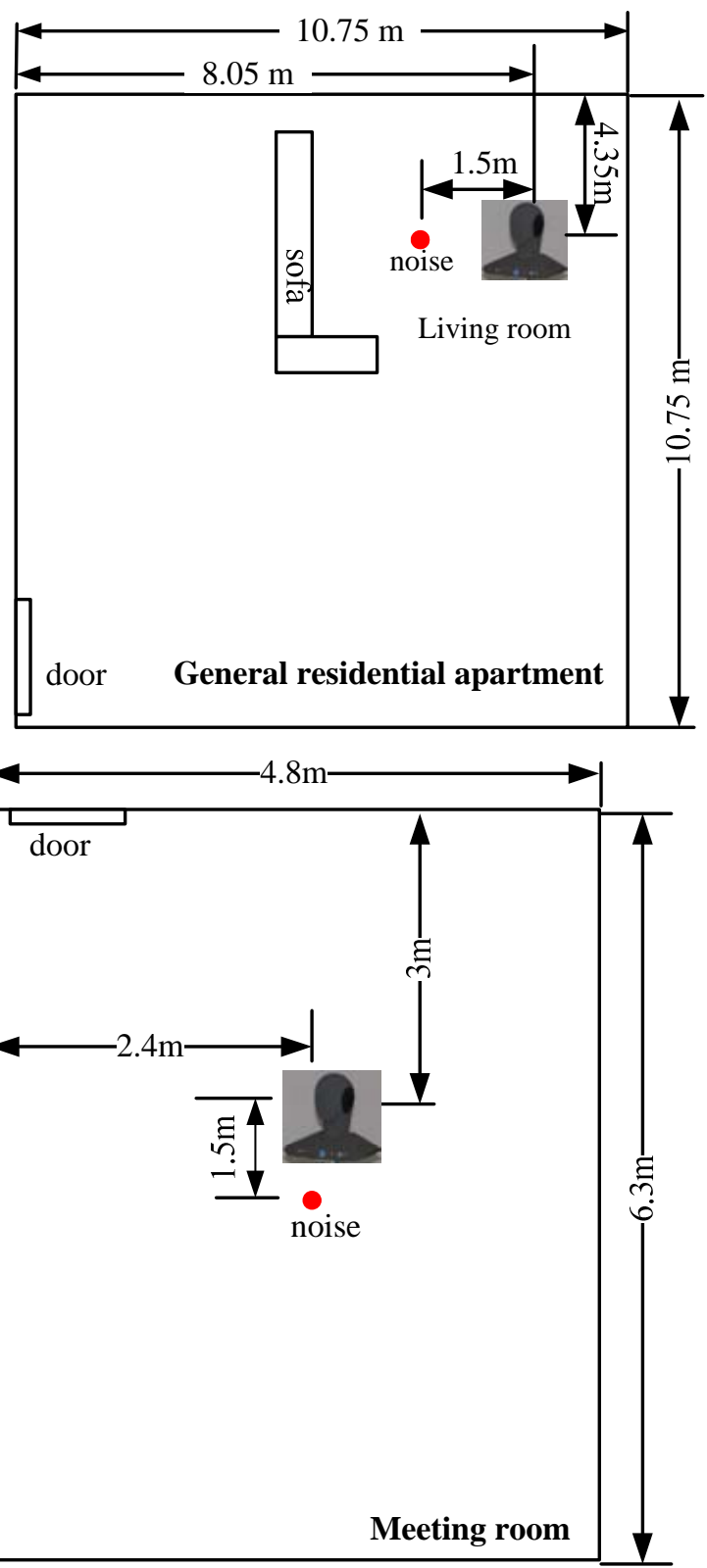

Fig. (5). Indoor space configurations adopted for experiments. 


\subsection{Measurement of Noise Sources}

Different sounds emanating from electrical appliances in a habitable space may cause annoyance and stress for some people $[13,14]$. Therefore, six different household electrical appliances were chosen to create the noise sample set, including a hairdryer, juicer, vacuum cleaner, extractor hood, shaver and bean grinder (see Fig. 6). The duration of noise source recordings was 10 seconds. Sound pressure level measurements and the calculated psychoacoustics parameters (loudness and sharpness) were analyzed using ArtemiS software. Subsequently, jury test results were obtained by statistical analysis (SPSS). All calculated results are given in Appendix-A. The jury test questionnaire was designed according to the results in Appendix-A and the corresponding data analysis.

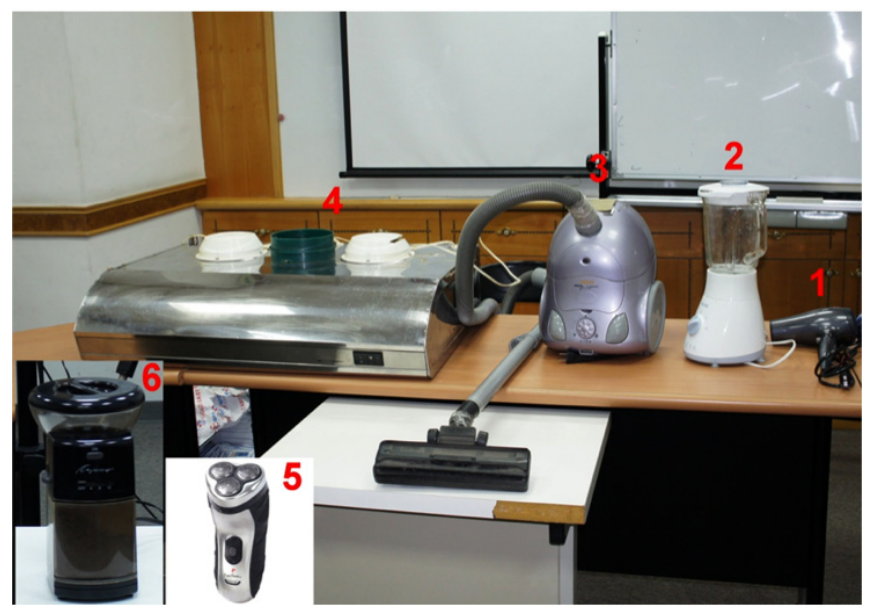

Fig. (6). Test sound sources consisting of six home appliances.

\section{JURY TEST PROCEDURE}

The jury test was carried out in different settings equipped with comfortable furnishings. Noise sources were controlled by a personal computer and were reproduced while the subjects were listening with headphones. Prior to the listening test, the purpose of the test and the testing procedure was explained to the subjects and the subjects' complete understanding of the significance of the test was confirmed. The two test methods used were paired comparison and category judgment. Loudness and sharpness were evaluated using paired comparison, and "degree of annoyance" and " degree of sharpness" were evaluated by the category judgment method.

\subsection{Subjects}

The ages of the 102 person jury ranged from 15 to 65 . The hearing abilities of the test subjects were normal. 62 of the subjects were female and 40 were male. The histogram of age distribution is shown in Fig. (7) and the occupation distribution is given in Table $\mathbf{1}$.

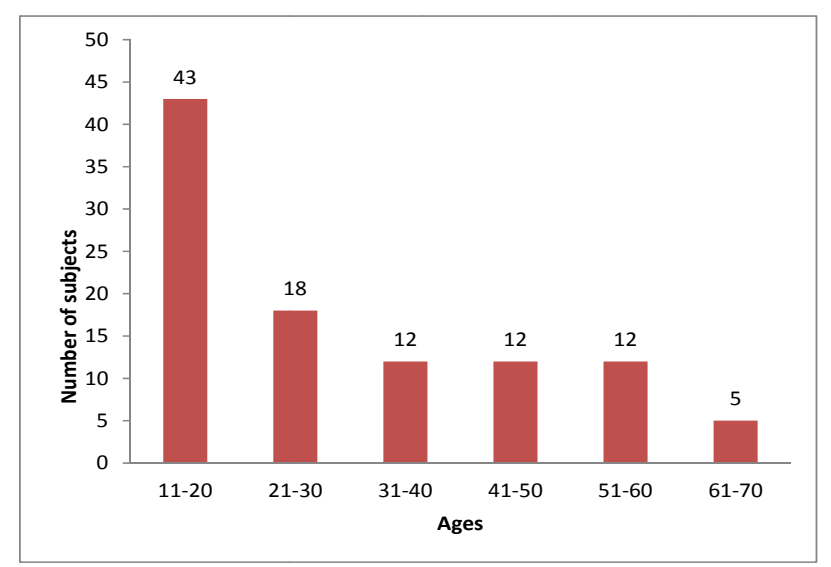

Fig. (7). Histogram of 102 subjects by age.

\subsection{Paired Comparison Method}

The paired comparison method is suitable for evaluating the difference between very similar sound sources [15]. This method was used to test the psychoacoustic parameters of loudness and sharpness. The technique requires that the subjects listen to a sequence of paired test noise sources, A and B. For each pair, the subjects must decide which one is louder and sharper. This method enables the subject to qualify their hearing perception based on two noise source samples to enable a more effective way to answer the questionnaire. The operating interface for this procedure is shown in Fig. (8).

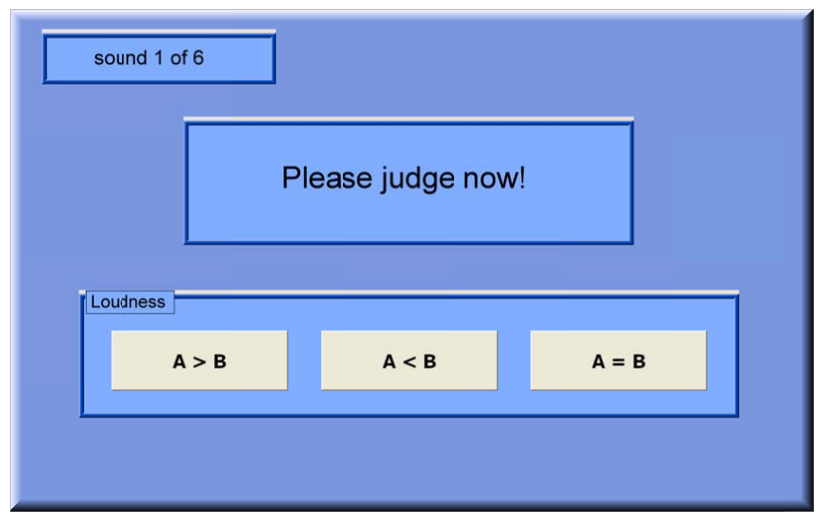

Fig. (8). Operating interface of paired comparison method.

Noise sources within the four indoor spaces generated six pairs of noise sources, and the assignment of these pairs is listed in Table 2. For each pair, one noise source sample

Table 1. Occupation Distribution of 102 Test Subjects

\begin{tabular}{|l|c|c|c|c|c|}
\hline Occupation & musician & student & housewife & engineer & researcher \\
\hline Number of Test subjects & 30 & 22 & 13 & 9 \\
\hline Occupation & office staff & attendant & repairman & retiree & janitor \\
\hline Number of Test subjects & 4 & 3 & 2 & 2 & secretary \\
\hline Occupation & accountant & professor & nurse & 1 & 1 \\
\hline Number of Test subjects & 2 & 1 & 1 & 1 \\
\hline
\end{tabular}


Table 2. The Space and Sound Distribution of the Paired Comparison Method

\begin{tabular}{|c|c|c|c|c|c|c|}
\hline \multirow{2}{*}{ Psychoacoustics Parameters } & \multicolumn{7}{|c|}{ Comparison Pairs for Four Room Types } \\
\cline { 2 - 7 } & Pair 1 & Pair 2 & Pair 3 & Pair 4 & Pair 5 & Pair 6 \\
\hline \hline Loudness & \multirow{2}{*}{ (R1,R4) } & (R2,R4) & (R2,R1) & (R3,R4) & (R3,R1) & $(\mathrm{R} 3, \mathrm{R} 2)$ \\
\hline Sharpness & & & & & \\
\hline
\end{tabular}

plays for 2 seconds with similar playback duration of 2 seconds for the other sample. During the playing of a noise source pair, the evaluation process displays three options: A equals B, A is greater than B, and A is less than B. Subjects decide on the appropriate response according to their subjective auditory experiences.

With reference to Tables A1-A4 for each indoor space, the noise sources with the maximum loudness and sharpness were found to be the juicer and shaver, respectively. In particular, the sharpness of the juicer in the general residential apartment and the meeting room was found to be greater than the shaver, but it clearly had a higher level of loudness than the other five household electrical appliances. Hence, only the juicer need be used in the testing of loudness.

\subsection{Category Judgment Method}

In this method, the noise sources are played one by one to the subjects, who evaluate each sound using the 7-point Rohrmann scale [16]. Each noise is judged independently. Therefore, it can be assumed that the results do not represent a simple comparative scale, but a scale that also allows the amount of difference between the sounds to be evaluated [17].

Noise sources including the vacuum cleaner, juicer and extractor hood were used to test the "degree of annoyance," which is divided into seven categories: $1=$ not in the least annoying; 2 = a little annoying; 3 = somewhat annoying; $4=$ annoying; 5 = more annoying; $6=$ much more annoying; and $7=$ most annoying. The shaver, hairdryer and bean grinder were used to test the "degree of sharpness," which is also divided into seven categories: $1=$ not in the least; $2=$ a little; $3=$ some; $4=$ sharp; $5=$ sharper; $6=$ much sharper; and $7=$ sharpest. The operating interface used to assign the 7category scale is shown in Fig. (9).

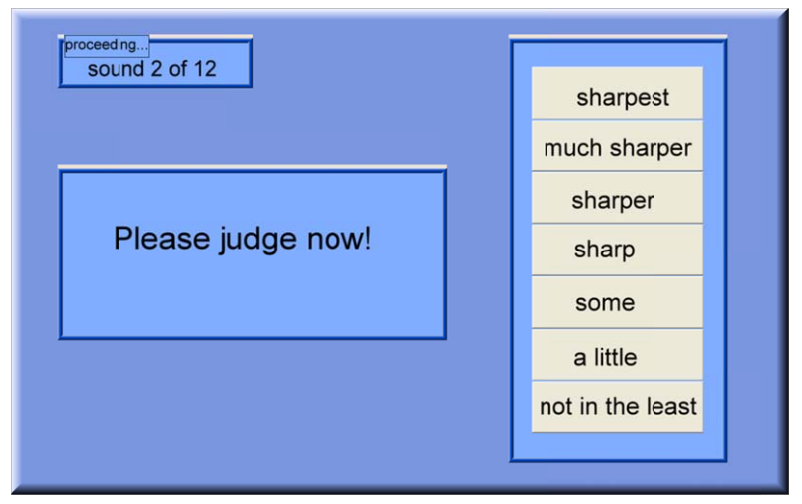

Fig. (9). Operating interface for the category judgment method.

\section{RESULTS AND DISCUSSION}

Six pairs of noise sources were generated within the four testing spaces, which equates to 612 paired source judgments. Table 3 shows the results of the judgments by percentage, and Figs. $(10,11)$ presents the findings for the parameters of loudness and sharpness. Based on these findings, loudness is $\mathrm{R} 2>\mathrm{R} 3>\mathrm{R} 1>\mathrm{R} 4$, and sharpness is R3 $>\mathrm{R} 1>\mathrm{R} 2>\mathrm{R} 4$. $36 \%$ of the subjects considered the juicer in the general residential apartment to be the loudest, and $33 \%$ of the subjects indicated that the shaver exhibits the highest level of sharpness in the small apartment suite. Loudness results show: higher background noise of the indoor space, the human auditory perception becomes louder. Background noise is low, such as high-rise apartment, makes people feel loudness much lower. Sharpness of the auditory perception directly from the noise source itself, independent of the interior space of the background noise.

Specifically, the loudness results from the paired comparison method (see Table 3) and the findings of the computational analysis (see Tables A2 and A3 in Appendix A) are inversely. Table A2 shows a loudness sensation of 38.67 sone in the general residential apartment, and Table A3 shows 39.85 sone in the small apartment suite. The reason for this is that out of the 612 pooled numbers, there was a $7 \%$ response for $\mathrm{R} 2=\mathrm{R} 3$. Subjects perceived the loudness of noise sources in a general residential apartment and a small apartment suite to be equivalent. This finding closely correlates to the values obtained from analysis of these two spaces and therefore, the test results are deemed self-consistent.

Under the category judgment method, the main purpose is to analyze the distribution trend of the overall noise sources. In other words, the 12 noise sources in the indoor spaces can be effectively understood in terms of human hearing perception. The resulting degrees of annoyance are shown in Fig. (12) and Table 4. The juicer annoys most subjects to a greater degree than the other noise sources, especially in the general residential apartment (R2), where it almost approaches the "much more annoying" category. The statistical analysis of R2 yields an average value of 5.68 with a standard deviation of 0.98 . Based on this number, the noise is enough to affect people's moods. Fig. (13) and Table 5 show that subjects in R1, R2 and R3 perceived a higher level of sharpness; statistical analysis of shaver in the three locations gives average values of $6.21,6.48$, and 6.16 respectively. Subjects perceived shavers to exhibit a high level of sharpness, as well as the juicer. This indicates that the juicer also causes annoyance and exhibits a high level of sharpness to the test subjects. 
Table 3. SPSS Analysis of the Results Obtained by the Paired Comparison Method

\begin{tabular}{|c|c|c|c|c|c|c|c|c|c|c|}
\hline \multirow{2}{*}{ Pair } & \multicolumn{5}{|c|}{ Room Category Number } & \multicolumn{5}{|c|}{ Room $A=$ Room $B$} \\
\hline & $\mathbf{R} 1$ & $\mathbf{R 2}$ & $\mathbf{R 3}$ & R4 & $\mathbf{R} 2=\mathbf{R} 1$ & $\mathbf{R} 3=\mathbf{R} 1$ & $\mathbf{R} 3=\mathbf{R} 2$ & $\mathbf{R 4}=\mathbf{R 3}$ & $\mathbf{R 4}=\mathbf{R} 2$ & $\mathbf{R} 4=\mathbf{R} 1$ \\
\hline loudness & $15 \%$ & $36 \%$ & $30 \%$ & $4 \%$ & $2 \%$ & $3 \%$ & $7 \%$ & $0 \%$ & $1 \%$ & $1 \%$ \\
\hline sharpness & $22 \%$ & $21 \%$ & $33 \%$ & $2 \%$ & $8 \%$ & $7 \%$ & $5 \%$ & $0 \%$ & $0 \%$ & $0 \%$ \\
\hline
\end{tabular}

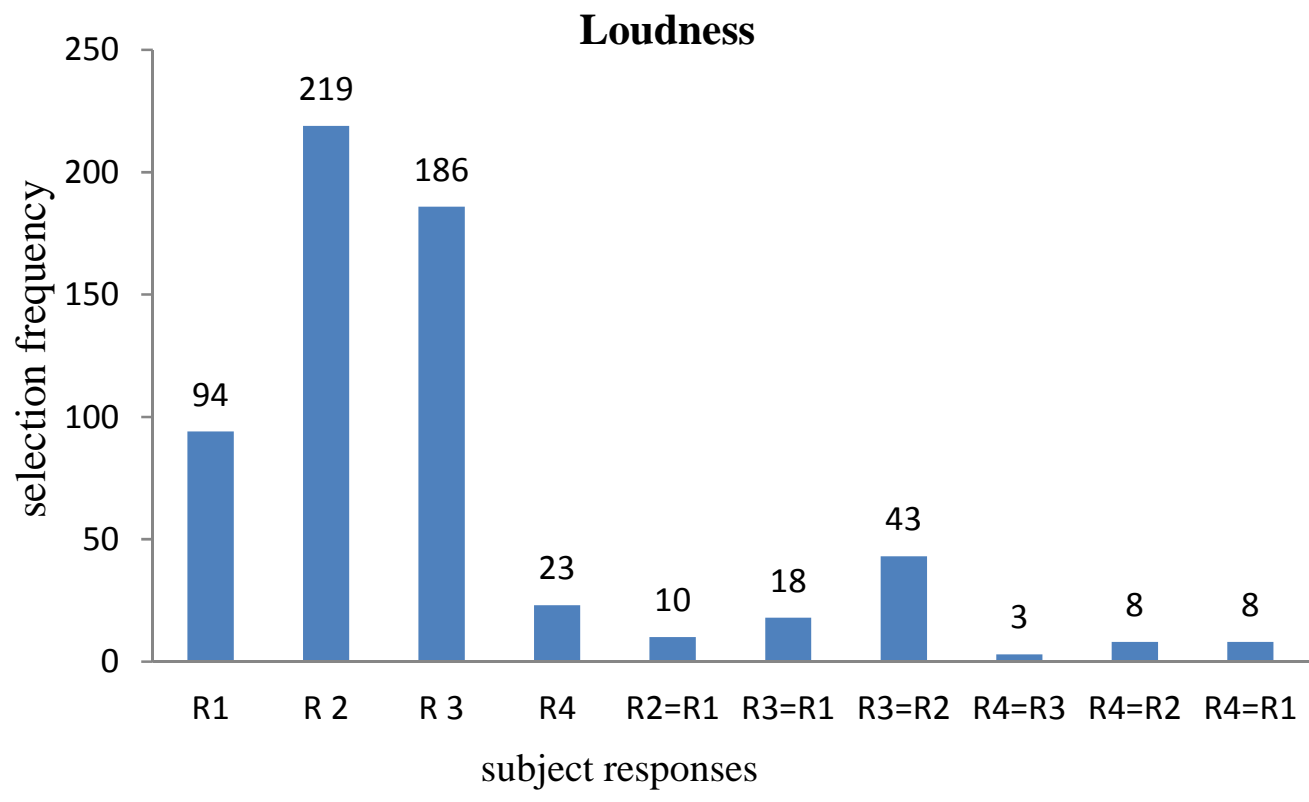

Fig. (10). The loudness results of paired comparison method.

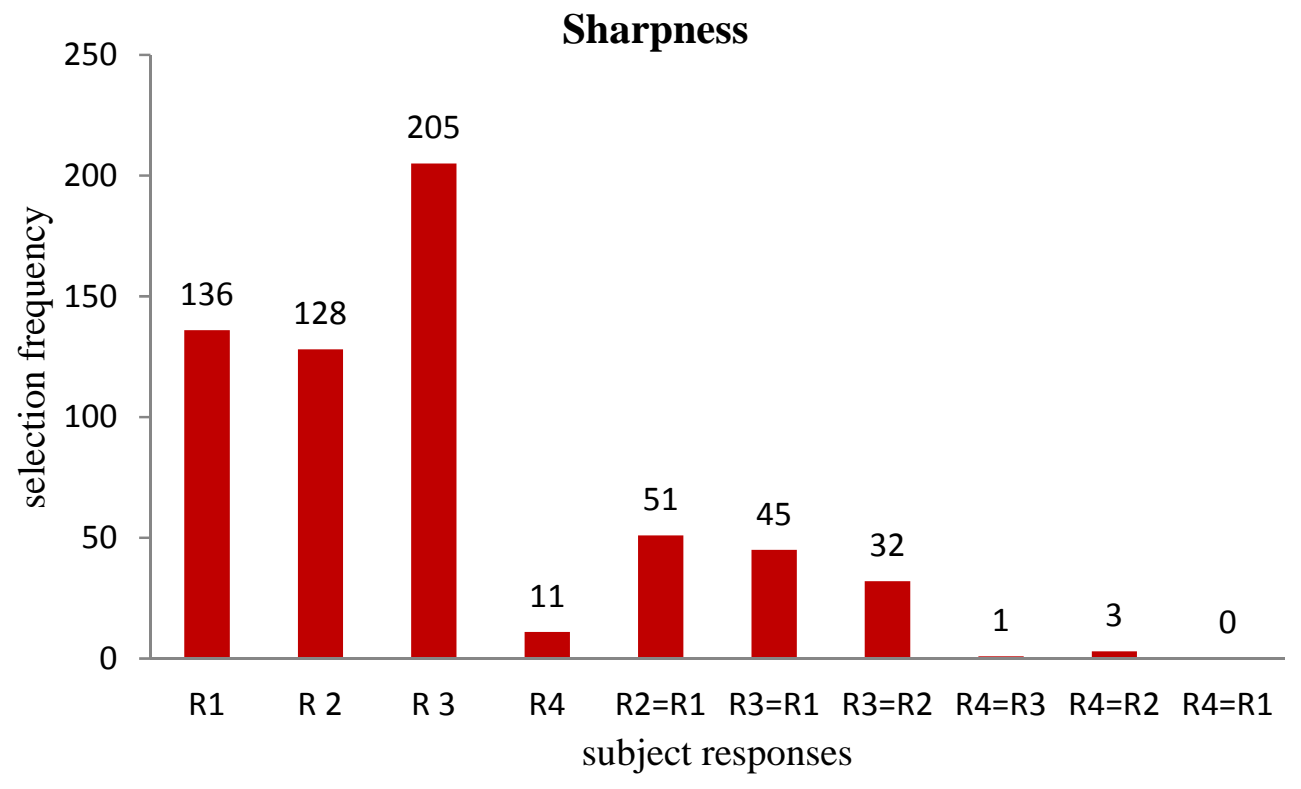

Fig. (11). The sharpness results of paired comparison method. 


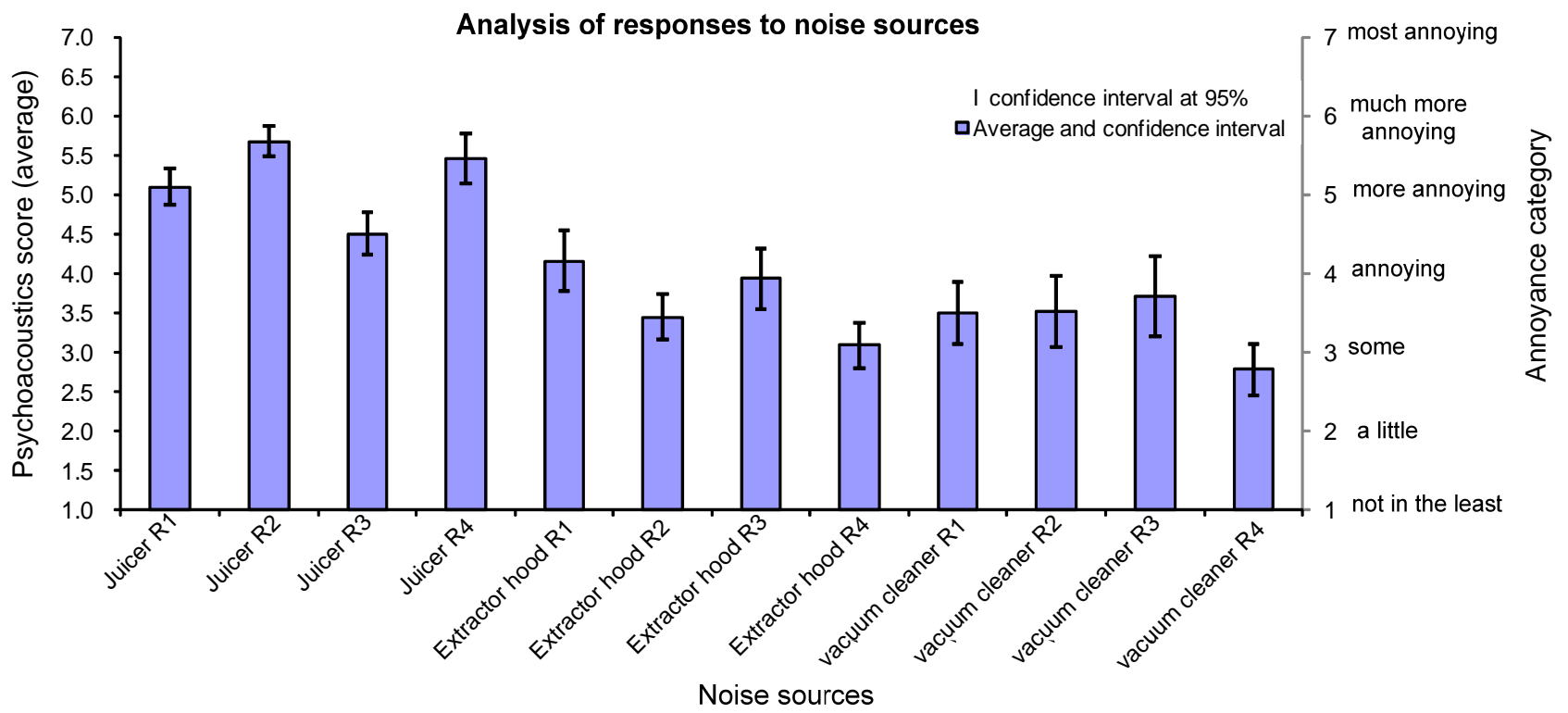

Fig. (12). Degree of annoyance using the category judgment method.

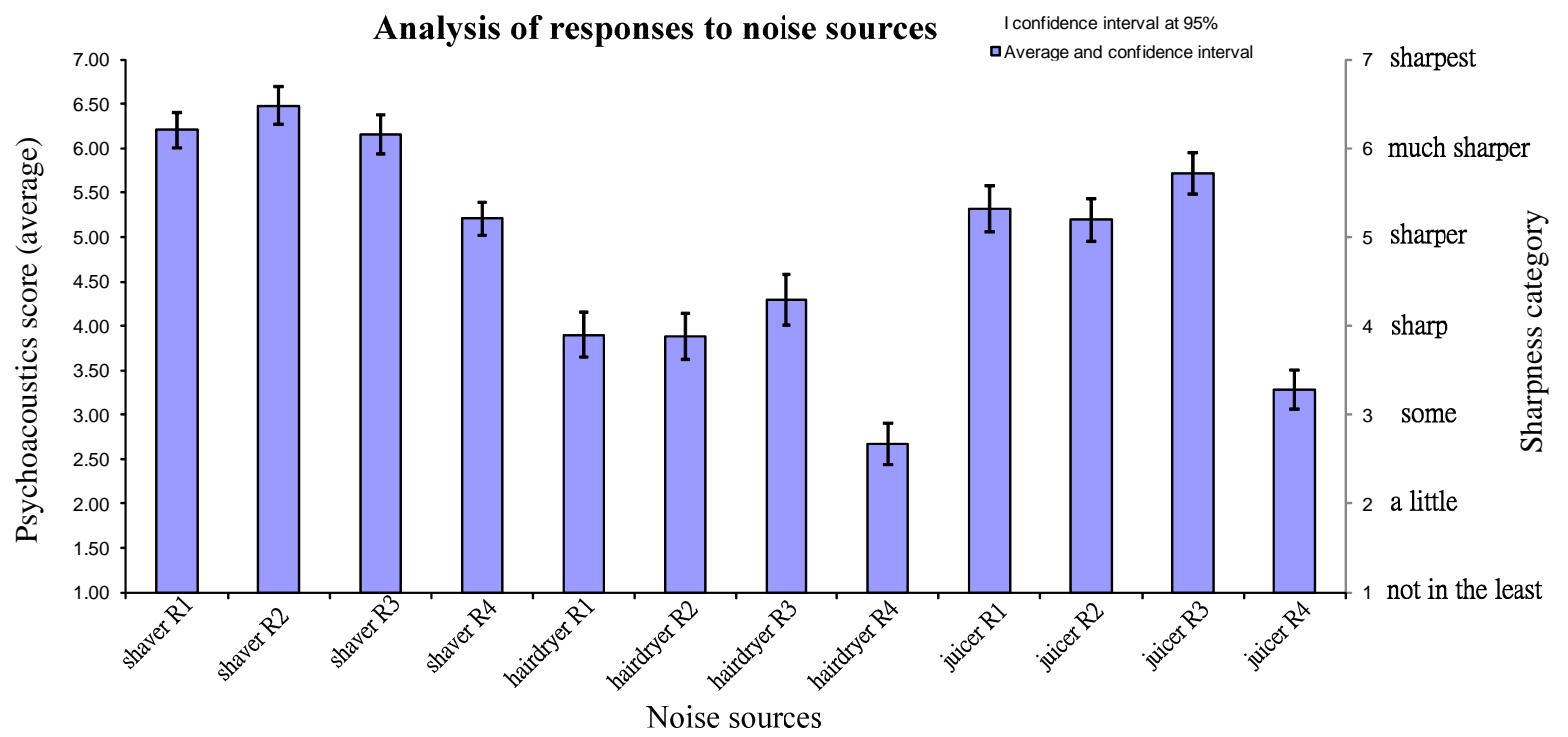

Fig. (13). Degree of sharpness using the category judgment method.

\section{CONCLUSION}

In this paper, a jury test procedure for evaluation of the sound quality of electrical appliances in indoor spaces was established. Using the paired comparison method, the results for noise sharpness are consistent with the jury test and artificial head measurement data. However, loudness results obtained in the general residential apartment (R2) and the small apartment suite (R3) are inconsistent. This is due to the close correlation between the psychoacoustic values. Therefore, the relationship between measurement data for psychoacoustics and the topic of human hearing perception requires further investigation.
From the selection of noise sources and indoor spaces, the design of the questionnaire, to the selection of the subjects, all of these considerations associated with human hearing perception were made based on a representative jury test group in Taiwan. The measurement and evaluation procedures used to assess noise due to electrical appliances in indoor spaces are helpful in determining a sound quality criterion as a parameter of psychoacoustics within different indoor spaces. This criterion could be used to evaluate the sound quality of other products. Human hearing perception is a complex subject. A single sound pressure level cannot describe all of the different aspects of sound quality in an indoor space. Binaural technology provides additional 
psychoacoustic information to judge the sound quality more accurately.

Table 4. SPSS Analyzed Results of Annoyance

\begin{tabular}{|c|c|c|c|}
\hline $\begin{array}{c}\text { Noise Source } \\
\text { Analysis }\end{array}$ & Average & $\begin{array}{c}\text { Standard } \\
\text { Deviation }\end{array}$ & $\begin{array}{c}\text { Confidence } \\
\text { Interval (95\%) }\end{array}$ \\
\hline \hline juicer R1 & 5.10 & 1.19 & 0.23 \\
\hline juicer R2 & 5.68 & 0.98 & 0.19 \\
\hline juicer R3 & 4.50 & 1.38 & 0.27 \\
\hline juicer R4 & 5.46 & 1.64 & 0.32 \\
\hline extractor hood R1 & 4.16 & 1.99 & 0.39 \\
\hline extractor hood R2 & 3.45 & 1.51 & 0.38 \\
\hline extractor hood R3 & 3.93 & 1.96 & 0.28 \\
\hline extractor hood R4 & 3.09 & 1.46 & 0.39 \\
\hline vacuum cleaner R1 & 3.50 & 1.99 & 0.44 \\
\hline vacuum cleaner R2 & 3.52 & 2.28 & 0.51 \\
\hline vacuum cleaner R3 & 3.71 & 2.62 & 0.32 \\
\hline vacuum cleaner R4 & 2.78 & 1.65 & \\
\hline
\end{tabular}

Table 5. SPSS Analyzed Results of Sharpness

\begin{tabular}{|c|c|c|c|}
\hline $\begin{array}{c}\text { Noise Source } \\
\text { Analysis }\end{array}$ & Average & $\begin{array}{c}\text { Standard } \\
\text { Deviation }\end{array}$ & $\begin{array}{c}\text { Confidence } \\
\text { Interval (95\%) }\end{array}$ \\
\hline \hline shaver R1 & 6.21 & 1.03 & 0.20 \\
\hline shaver R2 & 6.48 & 1.08 & 0.21 \\
\hline shaver R3 & 6.16 & 1.12 & 0.22 \\
\hline shaver R4 & 5.21 & 0.98 & 0.19 \\
\hline hairdryer R1 & 3.90 & 1.29 & 0.25 \\
\hline hairdryer R2 & 3.88 & 1.37 & 0.27 \\
\hline hairdryer R3 & 4.29 & 1.45 & 0.23 \\
\hline hairdryer R4 & 2.68 & 1.20 & 0.26 \\
\hline juicer R1 & 5.31 & 1.34 & 0.24 \\
\hline juicer R2 & 5.20 & 1.22 & 0.24 \\
\hline juicer R3 & 5.72 & 1.22 & 0.22 \\
\hline juicer R4 & 3.28 & 1.14 & \\
\hline
\end{tabular}

\section{CONFLICT OF INTEREST}

The authors confirm that this article content has no conflict of interest.

\section{ACKNOWLEDGEMENTS}

The authors thank for support by Bureau of Standards, Metrology and Inspection, M.O.E.A, R.O.C.

\section{APPENDIX A}

Measured sound pressure levels and calculated psychoacoustic parameters for electrical appliances in the four indoor spaces
Table A1. Highrise Apartment

\begin{tabular}{|c|c|c|c|c|}
\hline $\begin{array}{c}\text { Electrical } \\
\text { Appliances }\end{array}$ & $\begin{array}{c}\text { Background } \\
\text { Noise (dB) }\end{array}$ & $\begin{array}{l}\text { SPL } \\
\text { (dB) }\end{array}$ & $\begin{array}{l}\text { Loudness } \\
\text { (Sone) }\end{array}$ & $\begin{array}{c}\text { Sharpness } \\
\text { (Acum) }\end{array}$ \\
\hline hairdryer & \multirow{6}{*}{43.35} & 66.34 & 18.35 & 3.37 \\
\hline juicer & & 76.02 & 37.15 & 4.14 \\
\hline vacuum cleaner & & 76.90 & 34.30 & 3.39 \\
\hline extractor hood & & 69.22 & 20.90 & 2.49 \\
\hline shaver & & 56.46 & 5.76 & 4.93 \\
\hline bean grinder & & 74.57 & 32.70 & 3.86 \\
\hline
\end{tabular}

Table A2. General Residential Apartment

\begin{tabular}{|c|c|c|c|c|}
\hline $\begin{array}{c}\text { Electrical } \\
\text { Appliances }\end{array}$ & $\begin{array}{l}\text { Background } \\
\text { Noise (dB) }\end{array}$ & $\begin{array}{l}\text { SPL } \\
(d B)\end{array}$ & $\begin{array}{l}\text { Loudness } \\
\text { (Sone) }\end{array}$ & $\begin{array}{c}\text { Sharpness } \\
\text { (Acum) }\end{array}$ \\
\hline hairdryer & \multirow{6}{*}{56.75} & 67.16 & 20 & 3.26 \\
\hline juicer & & 76.61 & 38.67 & 4.50 \\
\hline vacuum cleaner & & 78.01 & 38.61 & 3.73 \\
\hline extractor hood & & 70.36 & 21.15 & 2.39 \\
\hline shaver & & 56.46 & 5.76 & 4.25 \\
\hline bean grinder & & 72.22 & 28.11 & 3.61 \\
\hline
\end{tabular}

Table A3. Small Apartment Suite

\begin{tabular}{|c|c|c|c|c|}
\hline $\begin{array}{c}\text { Electrical } \\
\text { Appliances }\end{array}$ & $\begin{array}{l}\text { Background } \\
\text { Noise (dB) }\end{array}$ & $\begin{array}{l}\text { SPL } \\
(\mathrm{dB})\end{array}$ & $\begin{array}{l}\text { Loudness } \\
\text { (Sone) }\end{array}$ & $\begin{array}{c}\text { Sharpness } \\
\text { (Acum) }\end{array}$ \\
\hline hairdryer & \multirow{6}{*}{49.71} & 68.64 & 21.85 & 3.46 \\
\hline juicer & & 77.10 & 39.85 & 4.39 \\
\hline vacuum cleaner & & 82.80 & 51.35 & 4.37 \\
\hline extractor hood & & 68.56 & 19.90 & 2.41 \\
\hline shaver & & 56.46 & 5.765 & 5.08 \\
\hline bean grinder & & 77.37 & 35.80 & 3.59 \\
\hline
\end{tabular}

Table A4. Medium Sized Meeting Room

\begin{tabular}{|c|c|c|c|c|}
\hline $\begin{array}{c}\text { Electrical } \\
\text { Appliances }\end{array}$ & $\begin{array}{l}\text { Background } \\
\text { Noise (dB) }\end{array}$ & $\begin{array}{l}\text { SPL } \\
\text { (dB) }\end{array}$ & $\begin{array}{l}\text { Loudness } \\
\text { (Sone) }\end{array}$ & $\begin{array}{c}\text { Sharpness } \\
\text { (Acum) }\end{array}$ \\
\hline hairdryer & \multirow{6}{*}{53.92} & 64.42 & 16.65 & 2.9 \\
\hline juicer & & 74.33 & 33 & 3.99 \\
\hline vacuum cleaner & & 75.85 & 29.15 & 2.98 \\
\hline extractor hood & & 70.22 & 19.10 & 2.08 \\
\hline shaver & & 56.46 & 5.76 & 3.59 \\
\hline bean grinder & & 73.31 & 28.65 & 3.45 \\
\hline
\end{tabular}




\section{REFERENCES}

[1] Giovanni BR, Francesco C, Michele C. Measurement of quantities depending upon perception byjury-test methods. Measurement 2003; 34: 57-66

[2] Kuwano S, Namba T, Hashimoto B, Berglund da rur A, Schick M. Florentine, Emotional expression of noise: A cross-cultural study. J Sound Vib 1991; 151(3): 421-8.

[3] Gierlich HW. The application of binaural technology. Appl Acoust 1992; 36: 219-43.

[4] Henrik M. Fundamentals of binaural technology. Appl Acoust 1992; 36:171-218

[5] Fastl H. The psychoacoustics of sound-quality evaluation. Acta Acust Acust 1997; 83: 754-64.

[6] Paul EG, Franlc JC, Yoram W. Subjective evaluation models and conjoint measurement. Behav Sci 1972; 17: 288-99.

[7] Patrick S, Stephen M, Suzanne W, Ivan P, Sandrine V, Xavier R. Characterizing the sound quality of air-conditioning noise. Appl Acoust 2004; 65: 763-90.

[8] Malcolm JC. psychoacoustics and product sound quality. In: Malcolm JC, Ed. Handbook of noise and vibration control. NY: John Wiley \& Sons, Inc. 2007; pp. 805-27.

[9] Genuit K. Standardization of Binaural Measurement Technique. J Physi III. 1992; 2: 405-7.
[10] Fischetti A, Hemim Y, Jouhaneau J. Differences between headphones and loudspeakers listening in spatial properties of sound perception. Appl Acoust 1993; 39: 291-305.

[11] Eberhard Z, Hugo F. On the Development of the Critical Band. J Acoust Soc Am 1972; 52: 699-702.

[12] Mutsumilshibashia AP, Fumiaki S, Hideki T. Relationships between arithmetic averages of sound pressure level calculated in octave bands and Zwicker's loudness level. Appl Acoust 2006; 67: 720-30.

[13] Jin YJ, Jin Y, Ho YC. Sound radiation and sound quality characteristics of refrigerator noise in real living environments. Appl Acoust 2007: 68: 1118-34.

[14] Jin YJ, Jong KR, PyoungJik L. A quantification model of overall dissatisfaction with indoor noise environment in residential buildings. Appl Acoust 2010; 71: 914-21.

[15] David HA. The method of paired comparisons. Proceedings of the $25^{\text {th }}$ conference on the design of experiments in army research developments and testing; 1979 Oct 17-19; Natick, Massachusetts: US Army Natick Research and Development Command 1960; pp. 1-16.

[16] Available at: http://www.rohrmannresearch.net/pdfs/rohrmann-vqsreport.pdf

[17] Head acoustics. Conducting listening test. Appl Note 2006; 1-17. 